\title{
Espetáculo e performance no Festival de Parintins
}

\author{
José Maria da Silva \\ Universidade Federal do Amapá, Macapá, Brasil \\ E-mail:jmsilva@unifap.br
}




\section{Resumo}

No presente artigo desenvolvo uma análise do festival que se realiza na cidade de Parintins, estado do Amazonas, o qual é realizado por duas agremiações de bois-bumbás - os bois Caprichoso e Garantido -, tendo como referência a teoria da performance. Para tanto, descrevo a estrutura do evento, a produção artística e as relações entre os elementos artísticos e a exibição. Procuro demonstrar que a dinâmica do espetáculo está intimamente ligada à dramaticidade dos atores em cena, às diferentes modalidades de artes e à atuação de personagens importantes no Festival: o apresentador e o narrador. Concluo que a performance de cada agremiação no Festival depende de uma série de fatores, os quais concorrem para a eficácia das exibições e a construção de representações e discursos sobre a Amazônia.

Palavras-chave: Performance. Dramaticidade. Boi-bumbá. Festival de Parintins. Amazonas.
Abstract

This essay offers an analysis of the Parintins Festival, Amazonas, held by two boisbumbás associations - the boi Caprichoso and boi Garantido, taking the theory of performance as its reference. I describe the structure of the event, the artistic production and the relations between artistic elements and the performance event. I seek to show that the dynamics of the performance is closely linked to the dramatic quality of the actors' presence, to the different artistic modalities and to the action of two important characters in the Festival: the announcer and the narrator. I conclude that the performance of each association in the Festival depends upon a series of factors, which compete for the efficacy of the exhibitions and the construction of representations and discourses about the Amazon.

Keywords: Performance. Dramatic quality. Boibumbá. Parintins' Festival. Amazon.

ILHA

volume 11 - número 1 


\section{Introdução}

7 êm sido cada vez mais crescentes os estudos sobre performance 1 na antropologia, de modo que podemos falar em uma área de pesquisa específica. O crescimento dessa temática é perceptível no Brasil, quando observamos sua presença nas reuniões de antropologia, da Anpocs e em outros eventos, assim como nos diversos trabalhos publicados sobre o assunto. ${ }^{1}$ Outro aspecto que indica o crescimento dos estudos de performance é a formação de núcleos de pesquisa em universidades brasileiras voltados ao tema (Langdon, 2008).

Neste artigo pretendo desenvolver uma análise sobre o papel da performance na dinâmica de um festival que se realiza todos os anos na cidade de Parintins (estado do Amazonas), evidenciando sua estrutura como evento e as relações entre os elementos artísticos e a exibição em cena. Procuro demonstrar como a concepção de espetáculo está intimamente ligada à performance de cada agremiação. Antes, faço uma breve introdução ao tema da antropologia da performance. Adianto que não é minha pretensão aqui fazer uma discussão exaustiva sobre o assunto - tarefa já empreendida por outros comentadores (Dawsey, 2005; Langdon, 2008; Peirano, 2006; Silva, 2005) -, mas, como disse, apenas uma introdução ao assunto.

Em uma mesa intitulada "Do ritual à performance: abordagens teóricas num campo emergente no Brasil", realizada por ocasião da 25a Reunião Brasileira de Antropologia, Mariza Peirano (2006) problematiza a pertinência dos estudos de performance na antropologia, perguntando se essa temática de estudo não estaria vinculada à ideologia ocidental. 
Todas as vezes que se aborda como a noção de performance entra no campo da antropologia, a fonte primeira é o trabalho pioneiro de Victor Turner. Contudo, Peirano questiona por que a antropologia da performance, sendo uma área nova de investigação, se baseia nos últimos trabalhos do autor, alguns dos quais publicados postumamente. Vale ressaltar que a noção de performance e os estudos correspondentes a essa abordagem não nascem na antropologia, mas, sobretudo, nos estudos sobre linguagem inspirados por um conjunto de autores da filosofia da linguagem e da linguística (Bauman, 1977; Bauman e Briggs, 2008; Langdon, 2008).

Sabemos que Turner desenvolveu estudos sobre performance a partir de duas experiências: os trabalhos de campo na África (sobretudo entre os Ndembu) e a inspiração originada no teatro, basicamente por influência de sua mãe (ver Turner, 1982). Na verdade podemos considerar que a ideia mesmo de performance em Turner resulta do desenvolvimento do conjunto de seus trabalhos, numa confluência entre o material etnográfico e a teoria, sendo esta oriunda de uma gama de influências (Durkheim, antropologia britânica, linguística, semiótica e hermenêutica).

Turner acurou suas observações tendo como base o comportamento do grupo no contexto de rituais e dramas, nos quais os atores expressavam suas posições, sentimentos, conflitos, formas de resolução dos conflitos e reajustamentos, em momentos especiais (Turner, 1974, 1994, 1996). Com relação à mudança na teoria antropológica (em direção à performance), o autor destaca e enfatiza a passagem da noção de estrutura para processo, de competência para performance, da lógica cultural para a dialética de processos socioculturais (Turner, 1982). A atenção, a partir desse momento, é dirigida para o uso da linguagem e para as diversas formas de comunicação na vida social. Vale lembrar que a linguagem, especialmente em sua expressão verbal, há muito tempo seduziu os antropólogos, que passaram a ver, particularmente na fala, elementos do comportamento humano relacionados à ação (Malinowski, 1930; Silverstein, 1997; Tambiah, 1985). Além disso, vale ressaltar a inspiração e o diálogo da antropologia estruturalista com a linguística de Saussure, 
especialmente com enfoque na língua (sistema), donde derivaram a concepção de estrutura e a análise de sistemas de comunicação e parentesco (Leach, 1977, 1985; Lévi-Strauss, 1982, 1985).

O ritual, que por muito tempo foi o foco de etnografias e análises antropológicas, em um primeiro momento foi identificado como categoria nativa para identificar momentos especiais, não rotineiros, através dos quais sociedades vivenciam e experimentam ciclos de vida - tempo privilegiado para que o pesquisador tenha acesso às ações e aos valores que são transmitidos. Em seguida passou a ser encarado como categoria conceitual e depois como estratégia de análise de evento, o que ampliou as possibilidades de aplicação dessa categoria (Leach, 1965; Peirano, 2001; Tambiah, 1985). Com base na filosofia pragmática da linguagem de Austin (1997), Tambiah expande a concepção de ritual e assim constitui uma teoria da ação. Nos rituais as pessoas não apenas comunicam algo, mas fazem alguma coisa. Dessa forma, os participantes de um ritual não saem da mesma forma com que entraram, pois são afetados pela experiência vivida nesse ritual.

Podemos, então, avançar e concluir que a concepção de performance permite a construção de um novo corpus teórico para a análise de experiências performativas de indivíduos (atores) em ação - o lugar da enunciação, a função, o discurso, o tom, o clima, os intervalos, o silêncio, enfim, uma gama de comportamentos e expressões que permitem a análise da dinâmica de um evento.

Paralelamente aos trabalhos de Turner na antropologia, outras concepções de performance foram desenvolvidas focalizando o teatro, a música, a dança, as interações sociais no cotidiano e as relações em diferentes esferas (Bauman, 2008; Kapferer, 1986; Schechner, 1986, 2000). O enfoque da performance nas interações sociais cotidianas tem sua inspiração em Goffman (1992) e se relaciona diretamente com a ideia de representação e desempenho de papéis. Estudos mais recentes têm nos mostrado que performance pode ser importante instrumental de análise em etnografias sobre experiências cotidianas (Bauman, 2008). Na verdade, a noção de performance nos permite criar novas formas de análise e, por conseguinte, contribuir com a teoria da ação social, na medida em que o 
comportamento das pessoas se expressa na ação, a qual pode se exprimir através da linguagem ou da manipulação de objetos. Nesse sentido, a análise da performance não se reduz a uma área específica - o teatro -, como muitas vezes se pensa, mas às diversas esferas que envolvem o indivíduo no cotidiano - política, negócios, música, direito, entre outras experiências humanas - ou em momentos especiais, como festas e outros eventos. Aliás, a própria ideia de performance não se limita a uma única concepção, pois há uma multiplicidade de abordagens de performance que não nos permite tratá-la como uma área de pesquisa homogênea, isto é, perceptível tanto pelos diferentes objetos de estudo quanto pelas inspirações teóricas que dão sustentação às análises.

\section{O Festival de Parintins}

Parintins é uma cidade conhecida no Brasil e no exterior porque ali se realiza todos os anos, no mês de junho, um evento da quadra junina denominado Festival Folclórico de Parintins. Trata-se de um espetáculo grandioso contracenado por duas agremiações de bois-bumbás, denominadas boi Caprichoso (identificado pela cor azul) e boi Garantido (simbolizado pela cor vermelha).

A pertinência, o reconhecimento e a legitimidade do boi-bumbá em Parintins se remetem ao processo histórico de colonização da Amazônia, quando em diferentes momentos (basicamente desde o século XIX) contingentes populacionais oriundos do Nordeste migraram para a região, atraídos principalmente pelos seringais e pelo boom da economia da borracha. Cronistas do século XIX registraram a presença de bois nas ruas de Manaus (Avé-Lallemant, 1980), e Galvão (1951) faz referência à existência de bois no Baixo Amazonas. ${ }^{2}$

A história dos bois Caprichoso e Garantido em Parintins remonta ao início do século XX, momento em que as duas agremiações reconhecem como o tempo de fundação de cada uma. Na verdade, por um longo período o espectro da chamada "brincadeira de rua" em Parintins era constituído por vários bois vinculados aos bairros da cidade. Nessa época, os bois se apresentavam nas ruas - ou nos ter- 
reiros localizados nos arredores das casas - e o enredo se baseava no drama da morte e na ressurreição do boi, também denominado "auto do boi".

Desse período origina-se o embate que fundamenta a rivalidade entre as duas agremiações e que atualmente estrutura o Festival. Até o início dos anos 1960, a rivalidade entre os bumbás se traduzia em confrontos entre ambos e cada um almejava a superioridade diante do adversário. A rivalidade incluía disputas realizadas através de versos entre os amos dos bois, bem como entre os próprios bois que se enfrentavam batendo a cabeça - um contra o outro. Essa disputa "corporal" quase sempre terminava em violência entre brincantes e torcedores, necessitando da intervenção da polícia, por isso o final da brincadeira era quase sempre na delegacia.

Portanto, a ideia de criação de um festival surgiu com a finalidade de acabar com a violência e definir uma outra forma para externar a rivalidade entre os contendores. Passou-se, então, de um confronto difuso e violento para um evento - na forma de competição - em que cada agremiação se exibe para uma plateia e um corpo de jurados. As apresentações dos bois-bumbás são feitas com base em um regulamento que define as regras da competição. Essa nova forma de rivalidade e disputa implicou, mais adiante, a transformação de uma manifestação de rua para um espetáculo com organização complexa, moderno e de massa.

A domesticação da rivalidade entre os bois de Parintins, que passou de confrontos violentos de rua para uma competição cujo resultado final é o título de campeão, nos remete à questão entre estrutura e história, mudança e permanência, abordada por Sahlins (1981) em sua análise sobre a chegada do capitão Cook no Havaí, no século XVIII, e sua recepção pela população nativa. Ao lançar mão da dualidade estrutura e evento, a partir da inserção de Cook na cultura havaiana, Sahlins evidencia a dialética entre história e estrutura, de modo que, para ele, a "história é organizada por estruturas de significação", de tal sorte que permite um reordenamento da cultura (1981, p. 7-8). Trazendo a proposta de análise de Sahlins para a festa dos bois de Parintins, pode-se afirmar que houve uma transforma- 
ção na forma como era praticada a rivalidade entre bois na cidade - a cultura local foi transformada de uma "brincadeira de rua", com o exercício da violência física, para um espetáculo moderno destinado a uma audiência. Ainda que tenha havido a domesticação da violência, os confrontos se mantêm, agora em outro plano, pois se trata de uma disputa mediada por regras, jurados e apresentações de cada agremiação no Festival. Ao final, importam o título de campeão e o menosprezo do adversário derrotado, por isso cada bumbá busca ao máximo uma boa performance em suas exibições e, com isso, impressionar a plateia e os jurados.

A questão, no entanto, não é apenas afirmar que houve mudança na rivalidade entre as duas agremiações, a partir da eliminação da violência, mas em que sentido mudou e em que base se estruturou, surgindo daí outra forma de manifestação constituída nessa relação de alteridades.

Os organizadores da competição foram, aos poucos, definindo o confronto entre os bois em um evento organizado e mediado por regras, com tempo, espaço e atores específicos para a realização.

O tempo já estava historicamente definido no ciclo das festas juninas - era uma tradição! -, no qual a população se organizava para as "brincadeiras" através de vários tipos de manifestações populares do período junino: bois, quadrilhas, pássaros, entre outros.

O espaço por algum tempo foi rotativo, quando os bois utilizavam quadras de escolas e clubes na cidade. Entretanto, apostando no potencial turístico da festa dos bois-bumbás, em 1988 o Governo do Estado do Amazonas concebeu um novo local para as apresentações das duas agremiações no Festival: o bumbódromo. Trata-se de um ginásio destinado às exibições nos dias do Festival.

Além disso, alguns fatores foram cruciais na constituição do novo espetáculo: i) a profissionalização do Festival, com corpo diretivo e a racionalidade que é própria das organizações modernas, sobretudo, com perspectiva econômica; ii) a aposta na adoção de conteúdos de inspiração regional: elementos da natureza amazônica, índios, caboclos, mitos, lendas, personagens, eventos históricos e símbolos considerados regionais; iii) a estruturação do evento como espetá- 
culo, cuja base são diferentes modalidades de arte; e iv) a incorporação de artistas locais na produção dos bumbás para as exibições.

O Festival é concebido pelos organizadores, pelos artistas e pelo público local como um evento de construção, reconstrução e atualização do regionalismo amazônico, ou seja, de uma identidade regional amazônica, de tal forma que eles costumam denominá-lo de “Ópera Amazônica". Porém, em que pese o discurso de identidade, o festival dos bois-bumbás incorpora e se relaciona, ao mesmo tempo, com diferentes esferas, agentes políticos, produtos e atores sociais, que, por um lado, produzem um caleidoscópio de relações e identidades e, por outro, impulsionam renovações e mudanças a cada edição do evento. Assim, a ideia de identidade amazônica é uma perspectiva entre tantas outras possibilidades de discursos e representações no contexto do Festival.

\section{A produção artística do Festival}

Produzido para um grande público, o Festival Folclórico de Parintins tornou-se o principal evento turístico da região, assim como um modelo para as diversas festas que se realizam em cidades próximas. ${ }^{3}$ Pode-se afirmar que há um ciclo próprio do boi-bumbá em Parintins, cuja estrutura apresenta o modelo próprio aos rituais estudados na antropologia (Leach, 1965; Peirano, 2001; Turner, 1974, 1994). O ciclo do boi-bumbá parintinense, portanto, se concretiza em uma sequência que engloba os três momentos de um ritual, que são a preparação, a realização e o encerramento.

O elemento-base de estruturação do Festival de Parintins é o regulamento, que define as regras da competição no âmbito do espetáculo, assim como o seu conteúdo. O Festival se realiza durante três noites seguidas, nas quais os bois Garantido e Caprichoso se apresentam em um tempo de aproximadamente duas horas e meia por noite. Uma regra fundamental do Festival é que cada apresentação é única, de modo que a agremiação não pode repetir alegorias, fantasias e conteúdos das exibições. Assim, cada bumbá se prepara para três diferentes dias de espetáculo. 
O regulamento estipula as apresentações em 22 quesitos - denominados localmente de itens -, sobre os quais os jurados emitem suas notas para cada agremiação. Há quesitos de personagens - boi, amo do boi, cunhã-poranga, pajé, sinhazinha da fazenda, porta-estandarte, rainha do folclore, tribos indígenas, tuxauas, figuras típicas regionais etc. - e de temáticas, tais como lenda amazônica, ritual e figuras típicas regionais.

Música, artes plásticas, dança e artes cênicas são modalidades artísticas que formam a base de produção do Festival, a partir da combinação de conhecimentos, habilidades e técnicas artísticas aliadas à bricolagem. Os artistas que trabalham nos bois são da própria cidade e desde cedo desenvolvem habilidades e técnicas artísticas voltadas à produção dos bois-bumbás. Há mais de dez anos os artistas parintinenses passaram a trabalhar também na produção artística das escolas de samba nas principais capitais do país, principalmente no Rio de Janeiro, o que lhes proporciona intercâmbio e novas experiências nos bastidores do Carnaval (Silva, 2007).

A música recebe o nome de toada, sendo o elemento que propicia os temas e os conteúdos das apresentações. Cada boi lança um CD de toadas por ano, contendo cerca de 12 ou mais músicas, com temáticas que abordam os mais diversos quesitos do Festival: personagens e temas relacionados à apresentação, tais como ritual e lenda amazônica.

Os bois contratam artistas plásticos e uma gama de profissionais (artesãos, costureiras, técnicos em ferragem, entre outros) para a elaboração de alegorias e fantasias. Na produção artística, as letras das toadas são traduzidas em material visual, cores e sons. Assim, na arena do bumbódromo, personagens, histórias de populações regionais (principalmente índios e ribeirinhos), mitos, ritos de iniciação, fenômenos da natureza e paisagens adquirem sentidos através da exibição de cenários e da dramaticidade de brincantes e figurantes.

A produção artística de cada boi-bumbá é precedida de pesquisas e levantamentos de informações sobre grupos indígenas (região de origem, história, mitos, vestuário, costumes, ritos de iniciação, alimentação, religiosidade etc.), populações ribeirinhas (com desta- 
que para o caboclo), ambientes e paisagens da região e pessoas de destaques que são homenageadas, sendo estas principalmente de Parintins. A pesquisa que antecede os trabalhos de bastidores dos galpões é, segundo as diretorias de arte dos bumbás, de suma importância para as exibições na arena do bumbódromo, pois a ideia dominante é apresentar ao público aspectos que singularizam a Amazônia. Nesse sentido, alguns elementos são apresentados como emblemas dessa Amazônia imaginária dos bois. Da natureza destacamse a floresta, os rios, a vitória-régia, a cobra-grande, o boto, entre outros aspectos. No que concerne às populações, o discurso do boibumbá privilegia o índio e o caboclo como sendo populações "autenticamente" amazônicas.

Após os levantamentos realizados por cada diretoria de arte, definem-se paisagens naturais, grupos sociais e aspectos culturais que serão objetos de abordagem para o Festival. Os dados são repassados aos compositores, que, com base nas informações, elaboram as toadas. Essas servem de inspiração para a produção artístico-visual do espetáculo.

Os artistas utilizam uma sequência técnica e metodológica para alcançar o êxito esperado como resultado final: primeiro, elabora-se um esboço da fantasia, alegoria ou cenário em forma de desenho, às vezes o desenho dá espaço a uma maquete (principalmente quando se trata de cenário com representações de animais, personagens e paisagens); em sequência, elabora-se uma estrutura feita com ferragem que dá forma e tamanho ao artefato, o qual finalmente recebe o acabamento com diversos tipos de materiais, atingindo a forma artística - fantasia ou alegoria. No caso das alegorias em que se procura representar paisagens, ou seja, "ambientes amazônicos" (rios, florestas, montanhas etc.), animais, seres mitológicos, figuras humanas, entre outras, as peças são sempre de grandes dimensões (chegando a medir 12 metros de altura), e na arena do bumbódromo formam-se cenários e seres gigantescos. Estes, por sua grandiosidade e movimento, reforçados pelos efeitos de luz, som e cor, criam um sentido espetacular, fantástico, para deleite e admiração da plateia. Afinal, é a Amazônia que está sendo apresentada em cena e isso tem um significado particular no discurso regionalista. 


\section{Espetáculo e performance}

O Festival de Parintins é um espetáculo que incorpora elementos de diferentes artes, sobressaindo-se, no entanto, o aspecto dramático em ações que sincronizam música, dança, artes visuais (sobretudo na formação de alegorias e grandes cenários) e expressões teatrais de brincantes e figurantes.

O palco das apresentações é um ginásio constituído de arena, cabines de jurados, camarotes, cadeiras numeradas e arquibancadas para as torcidas organizadas, estas últimas gratuitas. Os lugares na plateia são direcionados aos diferentes públicos, classificando-os pelos lugares ocupados nas áreas destinadas ao público e pelo engajamento na festa.

A plateia é composta de dois tipos de públicos: a torcida organizada de cada um dos bois - denominada de galera - e os visitantes. Estes, por sua vez, são distintos em visitantes oriundos de localidades do Amazonas e de outros estados da região, visitantes de outros estados do país e do exterior. Há ainda as celebridades convidadas pelos organizadores da festa - em geral, artistas, políticos e desportistas conhecidos. São pessoas cujas presenças conferem prestígio ao evento (Silva, 2007).

O envolvimento da plateia nas apresentações dos bumbás é previsto no regulamento, no quesito "torcida organizada". Assim, durante a apresentação de cada agremiação o público é envolvido nos diversos momentos do espetáculo, através de gestos, dos movimentos com adereços recebidos na entrada do ginásio, cantando e fazendo coreografias ensaiadas previamente. Portanto, nessa concepção de envolvimento da torcida no espetáculo, rompe-se com a relação distanciada entre palco e plateia, que predomina na maioria dos eventos dessa natureza.

Como se trata de um evento cuja base é a competição entre os dois protagonistas e a finalidade é o resultado - ganhar o título de campeão do Festival -, performance e eficácia devem ser vistas como complementares (pelo menos na intenção), ainda que nem sempre uma boa performance implique um resultado final positivo, por isso 
o período pós-Festival é sempre dominado por polêmicas e questionamentos sobre as notas dos jurados e o resultado.

As apresentações têm sentido linear e crescente com a finalidade de atingir o clímax do espetáculo. Normalmente começa com a apresentação de alguns personagens individuais - o boi, a porta-estandarte e a rainha do folclore -, passando por outros personagens e quesitos temáticos, como cunhã-poranga, tribos masculinas e femininas, figuras típicas e lenda amazônica, até o ponto alto da apresentação - o ritual. Denomina-se ritual uma parte da exibição (de inspiração indígena) na qual se dramatiza uma ação negativa aos figurantes "indígenas" e que tem a intervenção dos poderes mágico-religiosos do pajé - uma espécie de luta entre o bem e o mal.

Portanto, lenda amazônica e ritual são quesitos por meio dos quais os bois abordam narrativas - histórias, mitos, eventos, ritos de iniciação, entre outros - inspiradas em tribos indígenas e comunidades ribeirinhas da região. Para tanto, as diretorias de arte dos bois levantam dados e informações sobre costumes, narrativas, vestuários, artefatos, locais de concentração, tipos de dieta alimentar, língua, modos de falar, feitos heroicos, personagens considerados heróis e outros.

O apelo visual no Festival é um elemento forte, com predomínio de imagens icônicas de animais, personagens e ambientes. São grandes alegorias que ora formam imagens de animais, humanos ou espíritos, ora produzem grandiosos cenários de paisagens (montanhas, rios, florestas etc.). O sentido é mostrar uma Amazônia que é "real" como fonte de inspiração, mas que na arena do bumbódromo ganha contornos de uma Amazônia espetacular - imaginada, ilusória e idealizada -, em verdadeiras imagens metafóricas. A constituição dos cenários e das ações dramáticas no Festival está afinada com uma concepção de regionalidade na qual a busca da semelhança tem um papel relevante. Como o símbolo não é uma realidade empírica, rios, florestas, animais e personagens "típicos" são hiperdimensionados, seja em tamanho, seja em cores e sons, de modo a atingir o público em todos os sentidos - auditivo e visual. Em que pese um ambiente familiar, as representações da Amazônia no Festival ampliam, deslocam, superdimensionam e enaltecem os ambientes natural e social da região. 
Porém, é preciso ressaltar que a dualidade realidade e fantasia divide os dois bumbás. Para o boi Caprichoso, mesmo fazendo levantamento de informações, tendo como referência populações e ambientes supostamente "reais", o que se apresenta na arena do bumbódromo não é retrato da realidade, e sim fruto da imaginação dos artistas. Por sua vez, o boi Garantido defende a ideia de que a produção artística apresentada ao público deve ser fiel à realidade e à cultura dos grupos selecionados para serem retratados em suas apresentações. Nos últimos anos, no entanto, um aspecto da realidade contemporânea domina as apresentações de ambos os bois, qual seja: a apologia ao meio ambiente amazônico, com discursos de denúncia sobre a devastação da natureza e defesa à preservação. Na verdade, trata-se de uma sincronia com os discursos em voga no mundo sobre o meio ambiente mundial, os quais elegeram a Amazônia como locus privilegiado da agenda internacional sobre as mudanças climáticas e a preservação do meio ambiente. Isso mostra a perspectiva dinâmica de renovação e atualização do Festival, incorporando temas do momento que dialogam não apenas com o local, mas com outras esferas, inclusive o global.

Além da música e da arte visual, a apresentação na arena do bumbódromo é conduzida por diferentes personagens: o levantador de toadas, que interpreta as músicas; o amo do boi, que declama versos enaltecendo os personagens; o apresentador, cuja função é apresentar os quesitos e animar a torcida; e o narrador, que evidencia e realça o conteúdo que está sendo encenado. Portanto, a performance das apresentações se dá na sincronia entre a música, as imagens produzidas pelas alegorias e fantasias, a ação dramática dos atores em cena e a presença de dois elementos que singularizam o Festival: o apresentador e o narrador. ${ }^{4}$

O apresentador tem a função de comandar a animação da torcida, provocando uma interação entre arena e platéia e fazendo com que o espírito de festa e a idéia de congraçamento entre brincantes e espectadores se estabeleçam. Além disso, o apresentador dirige os quesitos na arena, informa e reforça para o público o sentido do que está sendo encenado ( Silva, 2007, p. 150). 
Na descrição do espetáculo, destacada a seguir, temos um exemplo da atuação do apresentador.

Com a música ao fundo, os movimentos das alegorias provocaram um "eclipse": efeitos de raios, clarões de fogos e faíscas riscaram a escuridão proporcionando uma imagem fulgurante ao espetáculo. A cobra-grande, recolhida no interior do tronco da árvore, "despertou" e mostrou-se "enfurecida". A personagem cunhã-poranga reforçou a cena ao mostrar-se "dopada", pois estaria dominada pela serpente. O apresentador enfatiza: “a cobra continua dominando a cunhã-poranga, que está em cima da serpente, e os índios continuam a atacar [...]" (p. 128).

O narrador, por sua vez, subsidia a plateia com informações externas, daí o seu caráter de reforço comunicativo. São informações sobre grupos indígenas e ribeirinhos, sua localização, costumes, vestuário "característico" de cada grupo, alimentação, entre outros aspectos. Vejamos a fala do narrador, com informações sobre os índios Mura que estavam sendo representados em uma exibição do boi Caprichoso:

Habitantes da região do baixo Purus, ao longo dos rios Solimões e Madeira. Eram verdadeiros índios aquáticos. Destacavam-se por adotarem a guerrilha como forma de combate para evitar o contato com os colonizadores e rechaçarem qualquer tentativa de invasão de seu território (p. 133).

A fala do narrador, em contexto, tem relevância no espetáculo "porque dá ao espectador as informações sobre as fontes de inspiração dos quesitos, narra as histórias [que estão sendo encenadas] fazendo com que pareçam situações concretas" (Silva, 2007, p. 150). Sua fala, portanto, possui força ilocucionária no evento, pois chama atenção para a cena, informa, reforça, amplia e, assim, contribui para a apresentação. Em outras palavras, proporciona à plateia dados que, em contexto, permitem uma dinâmica à exibição e, dessa forma, o espetáculo mistura imaginação e realidade e, consequentemente, produz cenas de hiper-realismo. 
Portanto, a performance no Festival de Parintins é uma combinação de múltiplas referências e funções: em um primeiro nível, situam-se as artes - música, dança, teatro e artes plásticas; em um segundo nível, tem-se as diversas possibilidades das representações e das imagens que criam a Amazônia para o público (objeto ideal da manifestação); em terceiro nível, a performance dos atores e dos brincantes na construção de seus personagens e na dramatização dos temas recorrentes; e, por fim, o desempenho comunicativo do apresentador e do narrador conduzindo o espetáculo.

Para os bois, a performance está diretamente ligada ao desempenho da agremiação para a conquista do Festival. Para isso, dependem dos artistas que são contratados e, consequentemente, da sua produção; dependem também da atuação dos brincantes e de uma exibição impecável na arena. Uma apresentação impecável é aquela que não só não tem problemas durante o espetáculo, mas que empolga a plateia e no outro dia é comentada pela cidade.

Para a plateia, a performance dos bois é avaliada na exibição de imagens e valores da Amazônia. Importa para o público, principalmente para os visitantes de outras regiões, a qualidade do espetáculo, não apenas em beleza estética, mas também no conteúdo apresentado sobre a região. O visitante que assiste ao Festival retorna com sensação de que conheceu um pouco mais a Amazônia. Nesse sentido, se, por um lado, Parintins é vista como metonímia do ambiente e da cultura regional, o espetáculo dos bois, por outro lado, apresenta na arena verdadeiras metáforas sobre a Amazônia, o que proporciona uma confusão entre realidade e fantasia. Essa é a força perlocucionária do espetáculo.

\section{Notas}

1 Ver Horizontes Antropológicos, n. 24, 2005 e Ilha: Revista de Antropologia, v. 8, n. 1/2, 2008.

2 Sobre a presença de bois em diversos locais do país, ver Doria (1991), Cavalcanti (2000) e Fernandes (2007).

3 Em várias cidades da região existem festas que se inspiraram no Festival de Parintins, seja com relação ao modelo de competição entre adversários, ao conteúdo que 
aborda a natureza e as populações regionais, seja na estruturação do espetáculo. Podemos citar como exemplo o Festival dos Botos, em Alter do Chão, e o Festival das Tribos, em Juruti, no estado do Pará; o Festival de Ciranda, em Manacapuru, e o Festival Folclórico de Manaus, no estado do Amazonas.

4 Às vezes as duas funções são exercidas por um único indivíduo.

\section{Referências}

AUSTIN, John L. How to do Things with Words. Cambridge: Harvard University Press, 1997.

AVÉ-LALLEMANT, Robert. No Rio Amazonas. Belo Horizonte: Itatiaia; São Paulo: Ed. USP, 1980.

BAUMAN, Richard. Verbal Art as Performance. Prospect Heights, Illinois: WaveWaveland, 1977.

. A poética do mercado público: gritos de vendedores no México e em Cuba. Antropologia em Primeira Mão, Florianópolis: Ed. UFSC, n. 103, 2008.

BAUMAN, Richard; BRIGGS, Charles L. Poética e performance como perspectivas críticas sobre a linguagem e a vida social. Ilha: Revista de Antropologia, Florianópolis: Ed. UFSC, v. 8, n. 1/2, p. 185-229, 2008.

CAVALCANTI, Maria Laura V. C. O Boi-Bumbá de Parintins, Amazonas: breve história e etnografia da festa. História, Ciências, Saúde: Manguinhos, Rio de Janeiro: Casa Oswaldo Cruz/Fundação Oswaldo Cruz, v. VI, p. 1019-1046, 2000. (Suplemento).

DAWSEY, John. O teatro dos "bóias-frias": repensando a antropologia da performance. Horizontes Antropológicos, Rio Grande do Sul: Ed. UFRGS, n. 24, p. 15-35, 2005.

DORIA, Siglia. 1991. O guardião do rito. Dissertação (Mestrado em Antropologia Social) - Programa de Pós-Graduação em Antropologia Social, Universidade de Brasília, Brasília, 1991.

FERNANDES, José G. S. O boi de máscaras: festa, trabalho e memória na cultura popular do Boi Tinga de São Caetano de Odivelas, Pará. Belém: Ed. UFPA, 2007.

GALVÃO, Eduardo. Boi-bumbá: versão do Baixo Amazonas. Anhembi, São Paulo: Anhembi, v. III, n. 7, p. 277-291, 1951.

GOFFMAN, Erwin. A representação do eu na vida cotidiana. São Paulo:

Perspectiva, 1992.

\section{ILHA}


KAPFERER, Bruce. Performance and the Structuring of Meaning and Experience. In: TURNER, Victor; BRUNER, Edward. The Anthropology of Experience. Chicago: University of IIinois Press, 1986. p. 188-203.

LANGDON, Jean E. Performance e sua diversidade como paradigma analítico: a contribuição de Bauman e Briggs. Ilha: Revista de Antropologia, Florianópolis: Ed. UFSC, v. 8, n. 1/2, p. 163-183, 2008.

LEACH, Edmund. Ritualization in Man in Relation to Conceptual and Social Development. In: LESSA, William; VOGT, Evon. (Ed.). Reader in Comparative Religion: An Anthropological Approach. New York: Harper and Row, 1965. p. 333-337.

. Cultura e comunicação. Rio de Janeiro: Zahar Editores, 1977.

. Aspectos antropológicos da linguagem: categorias animais e insulto verbal. In: DA MATTA, Roberto (Org.). Edmund Leach. São Paulo: Ática, 1985. LÉVI-STRAUSS, Claude. As estruturas elementares do parentesco. Petrópolis: Vozes, 1982.

. A análise estrutural em lingüística e em antropologia. In:

Antropologia estrutural. Rio de Janeiro: Tempo Brasileiro, 1985a. p. 45-70. . Linguística e antropologia. In:

Janeiro: Tempo Brasileiro, 1985b. p. 85-99. . Antropologia estrutural. Rio de

MALINOWSKI, Bronislaw. The Problem of Meaning. In: OGDEN, Charles Kay; RICHARDS, I. A. (Org.). The Meaning of Meaning. Londres: Kegan Paul, 1930.

PEIRANO, Mariza. A análise antropológica de rituais. Série Antropologia, Brasília: Ed. UnB, 2000.

. Rituais como estratégia analítica e abordagem etnográfica. In:

. O dito e o feito: ensaios de antropologia dos rituais. Rio de Janeiro:

Relume Dumará, 2001. p. 7-14.

. Temas ou teorias? O estatuto das noções de ritual e de performance. Série Antropologia, Brasília: Ed. UnB, 2006.

SAHLINS, Marshall. Historical Metaphors and Mytical Realities. Ann Arbor: The University of Michigan Press, 1981.

SCHECHNER, Richard. Magnitudes of Performance. In: TURNER, Victor; BRUNER, Edward. The Anthropology of Experience. Chicago: University of IIinois Press, 1986. p. 344-369.

del Rojas, 2000.

. Performance: teoria y practicas interculturales. Buenos Aires: Libros 
SILVA, José Maria da. O espetáculo do boi-bumbá: folclore, turismo e as múltiplas alteridades em Parintins. Goiânia: Ed. UCG, 2007.

SILVA, Rubens Alves da. Entre "artes" e "ciências": a noção de performance e drama nas ciências sociais. Horizontes Antropológicos, Rio Grande do Sul: Ed. UFRGS, n. 24, p. 35-65, 2005.

SILVERSTEIN, Michael. Language as Part of Culture. In: TAX, Sol; FREEMAN, Leslie Gordon (Org. .). Horizons of Anthropology. Chicago: Aldine Publishing Company, 1997. p. 119-131.

TAMBIAH, Stanley J. Culture, Thought and Social Action. Cambridge: Harvard University Press, 1985.

TURNER, Victor. O processo ritual. Petrópolis: Vozes, 1974. . From Ritual to Theatre. New York: PAJ Publications, 1982. . The Anthropology of Performance. New York: PAJ Publications, 1988. . The Forest of Symbols: Aspects of Ndembu Ritual. Ithaca: Cornell University Press, 1994. . Schism and Continuity in an African Society. Oxford: Berg, 1996.

Recebido em: 07/10/2010

Aceite em: 07/11/2010 